\title{
Scale and Cross-Scale Dynamics: Governance and Information in a Multilevel World
}

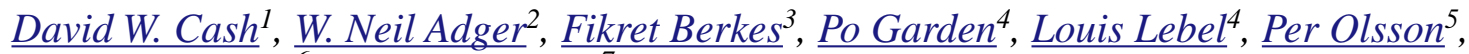 \\ Lowell Pritchard $^{6}$, and Oran Young $^{7}$
}

\begin{abstract}
The empirical evidence in the papers in this special issue identifies pervasive and difficult cross-scale and cross-level interactions in managing the environment. The complexity of these interactions and the fact that both scholarship and management have only recently begun to address this complexity have provided the impetus for us to present one synthesis of scale and cross-scale dynamics. In doing so, we draw from multiple cases, multiple disciplines, and multiple perspectives. In this synthesis paper, and in the accompanying cases, we hypothesize that the dynamics of cross-scale and cross-level interactions are affected by the interplay between institutions at multiple levels and scales. We suggest that the advent of co-management structures and conscious boundary management that includes knowledge co-production, mediation, translation, and negotiation across scale-related boundaries may facilitate solutions to complex problems that decision makers have historically been unable to solve.
\end{abstract}

Key Words: scale; level; cross-scale dynamics; boundary organization; co-management

\section{INTRODUCTION}

There is a long history of disappointments in policy, management, and assessment arising from the failure to take into proper account the scale and cross-scale dynamics in human-environment systems: collapsing fisheries, transboundary pollution problems, vulnerability to repeated extreme events like floods and droughts, and the inability to address human-induced disease outbreaks (Millennium Ecosystem Assessment 2005).

The benefits of recognizing scale challenges in policy integration have also been well documented. Experience shows that recognition and successful exploitation of cross-scale opportunities has been important for improving well-being: improvements in public health and education, the development and adoption of productivity-enhancing technologies in agriculture, innovations in social and environmental policy, and new organizational forms and management strategies in business (Lansing 1991, Folke et al. 2002, Gunderson and Holling 2002, Ostrom et al. 2002).
The implementation plan of the parties to the 2002 World Summit on Sustainable Development has 81 references to "at all levels" in just 50 pages. This could be read as either an acknowledgement that many problems have causes and solutions that span multiple levels or as an admission of ignorance or willingness to address particular levels and crosslevel interactions. Either way, understanding crossscale interactions in the human-environment system is seen as increasingly important.

This special issue brings together the work of a group of researchers who share a common interest in strengthening the capacity to analyze and resolve challenges arising from cross-scale dynamics. In this introduction, we suggest definitions and categories and identify key scale challenges. We end with a brief overview of some of the main findings across the studies in this special issue. 


\section{SCALES}

Following Gibson et al. (2000) we define "scale" as the spatial, temporal, quantitative, or analytical dimensions used to measure and study any phenomenon, and "levels" as the units of analysis that are located at different positions on a scale.

The best-studied scale is geographical space or the spatial scale (see Fig. 1A). Environmental, geophysical, and ecological phenomena occur over a continuous range of levels, although particular levels may be more important for particular processes. For example, complex cellular processes govern the decomposition of plant matter lying across a cleared patch of forest, releasing carbon dioxide into the atmosphere. Once released to the atmosphere, molecules of carbon dioxide rapidly merge into a somewhat uniform global mix of gases regulating the Earth's greenhouse effect. Global climate change may result from an amplified greenhouse effect. Thus, global systematic changes and phenomena are linked to and regulated by a complex mix of local processes and vice versa.

Just as spatial scale can be thought of as divided into different "levels," temporal scale can be thought of as divided into different "time frames" related to rates, durations, or frequencies (see Fig. 1B). Thus, biogeophysical phenomena happen at a range of different time frames. Examples are the coexistence of fast cellular metabolism, slow genetic changes, population dynamics that happen over generations, or events with an extremely rapid onset, such as volcanic eruptions or hurricanes. Similarly, phenomena of extremely long duration in global climate dynamics, such as sea temperatures, manifest themselves in changes in relatively shortlived hurricane regimes. Social phenomena also happen over a range of time frames: the 24-hr news cycle, electoral events that happen on the order of multiple years, the lifetime of bureaucratic agencies, or the long time frame of large cultural shifts in religion or in dominant economic paradigms and ideologies.

Closely related to spatial scale are jurisdictional scales defined as clearly bounded and organized political units, e.g., towns, counties, states or provinces, and nations, with linkages between them created by constitutional and statutory means (see Fig. 1C). Institutional arrangements, for example, not only have specific jurisdictional characteristics but also fall into a hierarchy of rules, ranging from basic operating rules and norms through to systems of rules for making rules or constitutions (Ostrom 1999; see Fig. 1D).

Although most attention given to scale in studies of human-environment interactions has focused on spatial, temporal, and jurisdictional issues, there are other scales that may be worth considering in particular cases (see Figs. 1E-1G).

Many environmental management plans and "actions," for example, can be grouped into hierarchical sets ranging from tasks through projects and strategies (see Fig. 1E). Although these relationships are not conventionally framed as a scale issue, we would argue that some of the challenges relating to mismatches may not always have so much to do with space as with the "scale" of management response and change. Some social networks may be "scale free" (e.g., Pastor-Satorras and Vespignani 2001), but others clearly have internal structures that may not be closely correlated with spatial scales. Hence, networks in markets and industries, through clans and religions, or even through professions and voluntary associations may be unrelated to political or geographic space (see Fig. 1F).

Finally, there are benefits to portraying aspects of knowledge as a scale (See Fig. 1G). First, there is often a gap between the highly generalized and generalizable understanding produced by formal science and the experientially and practice-based understanding embedded in both "modern" local and in "traditional" ecological knowledge. This gap can be framed as a lack of cross-level interaction in the knowledge system. Second, although knowledge of processes is useful at larger spatial and temporal scales, often it can only be applied by accepting a lower resolution and application of general processes to the local specific cases.

\section{CROSS-SCALE AND CROSS-LEVEL}

Interactions may occur within or across scales, leading to substantial complexity in dynamics. Although a more precise terminology for scale is not always essential, it does matter to the discussions in this paper and volume. "Cross-level" interactions refer to interactions among levels within a scale, whereas "cross-scale" means interactions across different scales, for example, between spatial domains and jurisdictions (see Fig. 2). "Multilevel" 
Fig. 1. Schematic illustrations of different scales and levels that arre critical in understanding and responding to human-environment interactions.

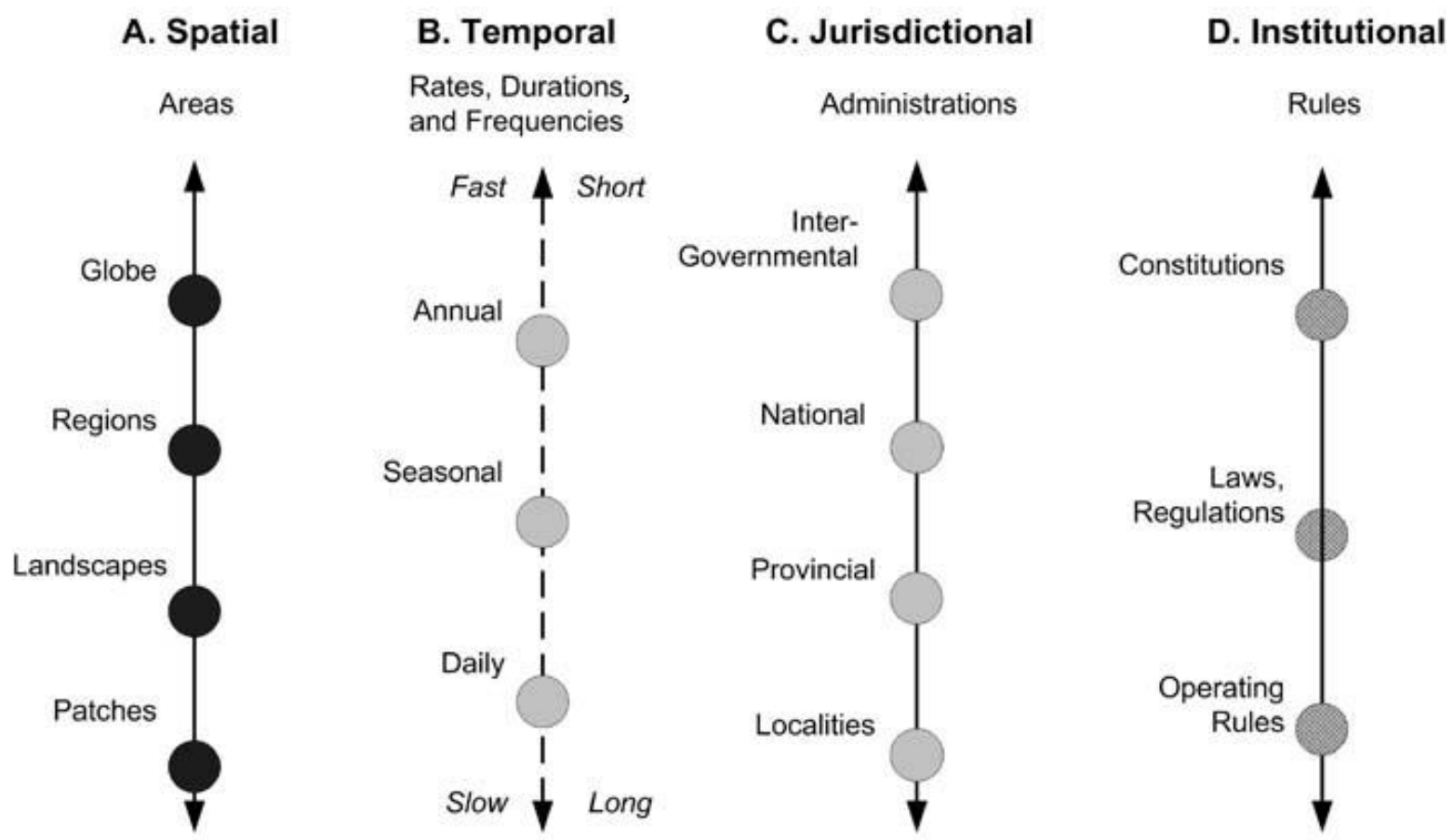

\section{E. Management}

Plans

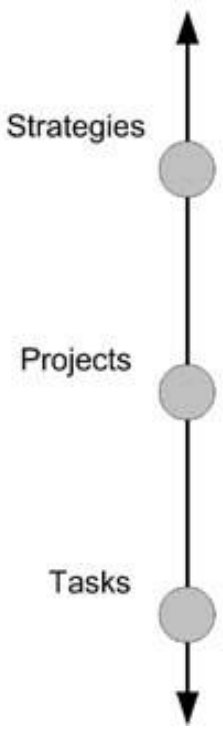

F. Networks

Links

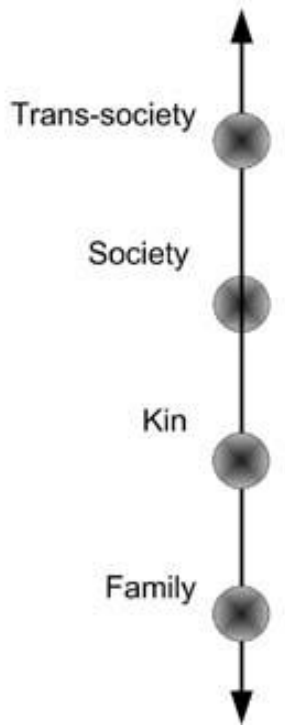

\section{G. Knowledge}

Truths

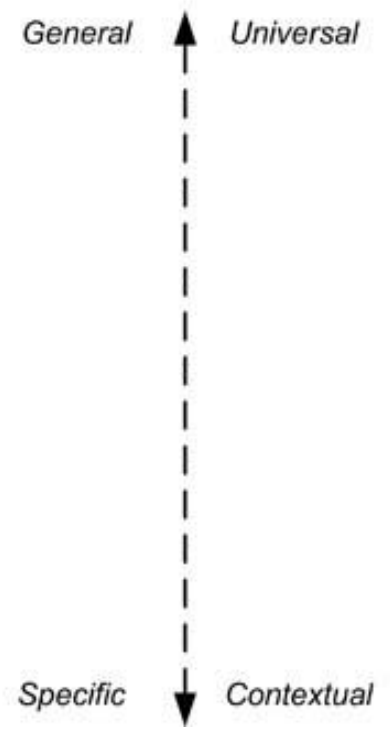


is used to indicate the presence of more than one level, and "multiscale" the presence of more than one scale, but without implying that there are important cross-level or cross-scale interactions.

Cross-scale and cross-level interactions may change in strength and direction over time. We refer to this type of changing interaction as the dynamics of the cross-scale or cross-level linkages. Changes may arise from the consequences of those interactions or be caused by other variables. For example, decentralization reforms can produce periods of strong interaction among high-level national institutions and those at the local government level during struggles involving power, responsibilities, and accountability relationships but then settle into a much more modest and steady level of interaction (Lebel 2006, Young 2006).

\section{CHALLENGES}

In this paper, a "scale challenge" is defined as a situation in which the current combination of crossscale and cross-level interactions threatens to undermine the resilience of a human-environment system. Three common challenges faced by society are: (1) the failure to recognize important scale and level interactions altogether, (2) the persistence of mismatches between levels and scales in humanenvironment systems, and (3) the failure to recognize heterogeneity in the way that scales are perceived and valued by different actors, even at the same level. We call these the scale challenges of "ignorance," "mismatch," and "plurality."

\section{Ignorance}

The most fundamental challenge is ignorance. The normal complexity of human-environment system dynamics observed at even one level on one scale may be such that attempting to understand, let alone influence, cross-level and cross-scale interactions may be extraordinarily difficult. Ignoring crossscale dynamics within spatial and temporal dimensions is common and leads to a range of management problems (Holling 1986, 1995, Clark 1987). Examples of these kinds of challenges in the management arena are national policies that adversely constrain local policies, local actions that aggregate into large-scale problems, and short-term solutions that aggregate into long-term problems. In addition, as noted above, scientific research often focuses on a single level and rarely examines the interactions of phenomena, either social or ecological, that cross levels.

\section{Mismatch}

The mismatch between human action and ecological systems is perhaps the archetypal scale problem, $i$. e., a problem of fit involving human institutions that do not map coherently on to the biogeophysical scale of the resource, either in space or time (Gibson et al. 2000, Young 2003). In these kinds of mismatch problems, the authority or jurisdiction of the management institution is not coterminous with the problem. Problems related to transboundary pollution, migratory fisheries (e.g., Berkes 2006), and aquifer management fall in to this category. More recently, the temporal-scale dimension of mismatch has been addressed. Temporal-scale mismatches arise, for example, in cases in which short electoral cycles conflict with long-term planning needs (Folke et al. 1998, Young 2003).

Another example of mismatch is the challenge of matching the scale of what is known about the world and the scale at which decisions are made and action taken (Kates et al. 2001). This is seen in the dual problems of large-scale scientific knowledge that has little relevance to local decision makers, e.g., global climate models that are at a resolution that is not useful to subnational decision making, or local, tacit, or indigenous knowledge that is not seen as credible by national or international actors, e.g., artisanal fishing knowledge that is not taken into account in international treaties on fisheries (Berkes 2002, Gadgil et al. 2003). The general result is the production of scientific and technical information that lacks salience, credibility, or legitimacy in the eyes of critical players at different levels (Cash et al. 2003).

\section{Plurality}

Another challenge arises out of the incorrect assumption that there is a single, correct, or best characterization of the scale and level challenge that applies to the system as a whole or for all actors. The consequences of a single set of solutions are often manifest in ineffective decisions and inequity in outcomes (Gibson et al. 1997, Cash and Moser 2000, Meadowcroft 2002, Ostrom et al. 2002). Different actors hope to gain different things from 
Fig. 2. Schematic illustrations of cross-level, cross-scale, multilevel and multiscale interactions.

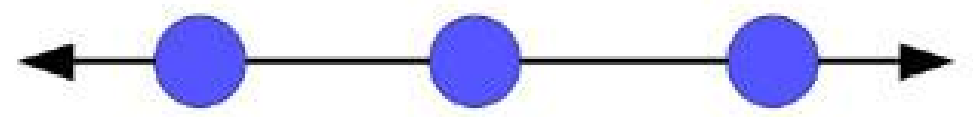

LEVEL

Multi-

Cross-

Multi-

Cross-
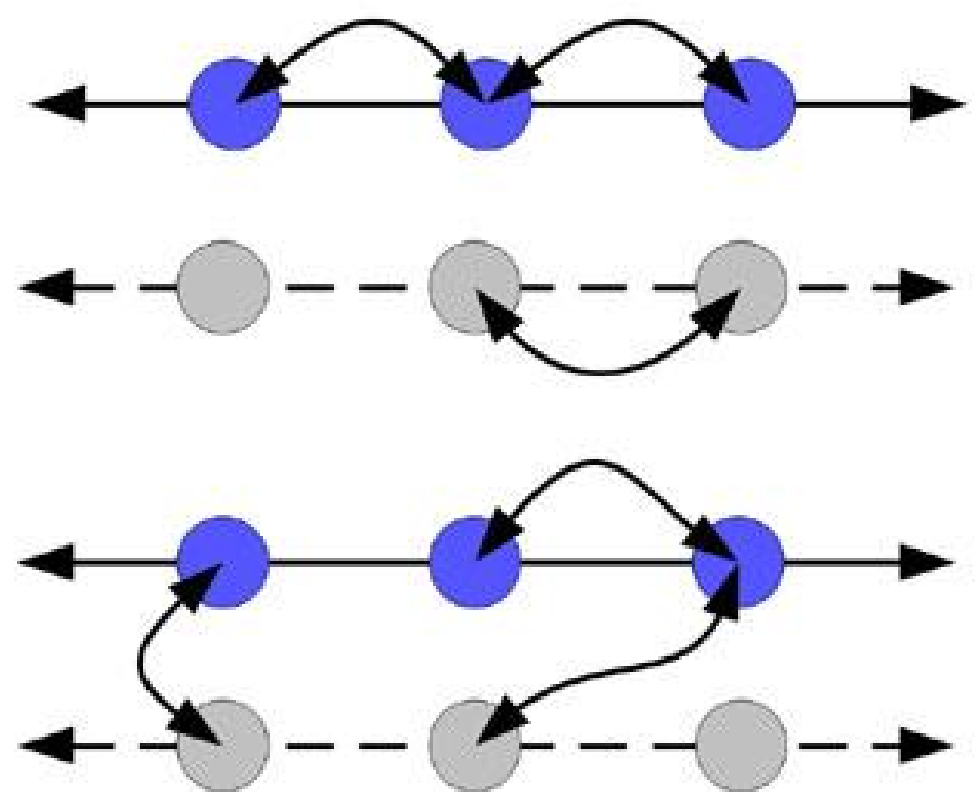

Cross-

Cross-
SCALE

Single-

Single-

Multi-

Cross- 
strengthening or weakening cross-scale linkages, and the new benefits and risks after such interactions are often not symmetric (Adger et al. 2006). This is one of the underlying reasons why scale issues are often strongly linked with political issues (Lebel et al. 2006). The implication is that procedures for scale choice, explanation, and resolution themselves need to be devised in ways that allow for the appropriate representation of scale-related interests. The outcome is likely to be a negotiated one rather than one that matches the criteria and preferences of one scale- or level-bound group of actors.

The simplest variant of this challenge is when a problem is defined as purely "global" or "local." Poignant examples include global environmental issues that make effective institutional solutions invisible by defining the problem as "global only" (Goldman 1998, Wilbanks and Kates 1999, Adger et al. 2001). The drive to frame issues at a single level comes from the need to both simplify and control. Governments, for example, frame problems so that they become tractable within their jurisdictions (Scott 1998, Lebel et al. 2006).

\section{Illustration}

These three challenges can be illustrated through a realistic, if generalized, example in agriculture. The spatial and temporal scales of research of the climate system and agricultural decision making are illustrated in Fig. 3. The mapping of research domains by spatial and temporal scales in Fig. 3 demonstrates that on-farm decision making and experimentation take place at a local level, i.e., spatial scale, and do not interact, in this schematic and illustrative case, with formal research or climate forecasting. Likewise, the slower, larger-level dynamics that are the focus of international climate research are not linked to the faster and smaller dynamics of interest to the agricultural extension system. The result in this system is, for example, an inability to relate an understanding of larger-scale climate dynamics to the decision-making needs of actors at lower levels. These are, in effect, challenges of institutional fit.

Now again consider the farmer who is making decisions about what crops to plant based on expectations about the security of water supplies, weather, and commodity prices at time of harvest. Without knowing that weather in the district is strongly influenced by El Niño and the Southern
Oscillation and that a dry-phase event is unfolding across the Pacific, farmers might make suboptimal decisions. However, if a national weather bureau is poorly connected to higher-level institutions of climate forecasting, it cannot know the impact of higher-level climate dynamics on national or local precipitation patterns. These are challenges that stem from ignorance.

From the perspective of the district water-resource manager charged with ensuring water supplies for irrigation during the dry season, both the larger and finer spatial and temporal variations are irrelevant. What matters is that the monsoon rains fill the dam by the end of the wet season. For the mayor of the city downstream, however, those late storms come when the rivers are already high and cause destructive floods. How should water levels in the dam be managed? These are challenges related to plurality.

\section{RESPONSES}

Scale challenges are pervasive, and the misconception of scale is part of the explanation of why societies throughout history have faced challenges of sustainability. Previous work on scale and other articles in this issue suggest that it might be possible to begin identifying common social and institutional responses to help address these challenges (Ostrom et al. 1999). Here we begin by exploring three responses already identified by others elsewhere, but brought together under the general rubric of responses to problems of scale and cross-scale interactions: institutional interplay, comanagement, and boundary or bridging organizations.

\section{Institutional interplay}

Cross-level interactions among resource regimes occur when there is vertical interplay between or among regimes located at higher and lower levels on the jurisdictional scale (Young 2006). In many cases, such interactions will involve interplay between management systems located at adjacent levels, e.g. interactions between state-level regimes administered by the Alaska Department of Fish and Game and national-level regimes administered by the U.S. Fish and Wildlife Service (see Young 2006). However, this is not always the case. For example, there are important cross-level interactions between the traditional practices of local Aboriginal 
Fig. 3. Schematic example of interaction across spatial, organizational, and temporal scales and levels. This schematic diagram can be used to illustrate the spatial and temporal dimensions of biogeophysical phenomena (the climate-related system represented as a solid line) and the interaction of two human domains: climate research (the long hashed line) and water management (hash-dotted lines). In this case, gaps exist in the human systems across levels within domains, e.g., international climate research does not link with national or subnational research or forecasting, and national water policy does not link with local water management) and across scales. This diagram is based on an original figure by Clark (1987) with recent additions by Lebel.

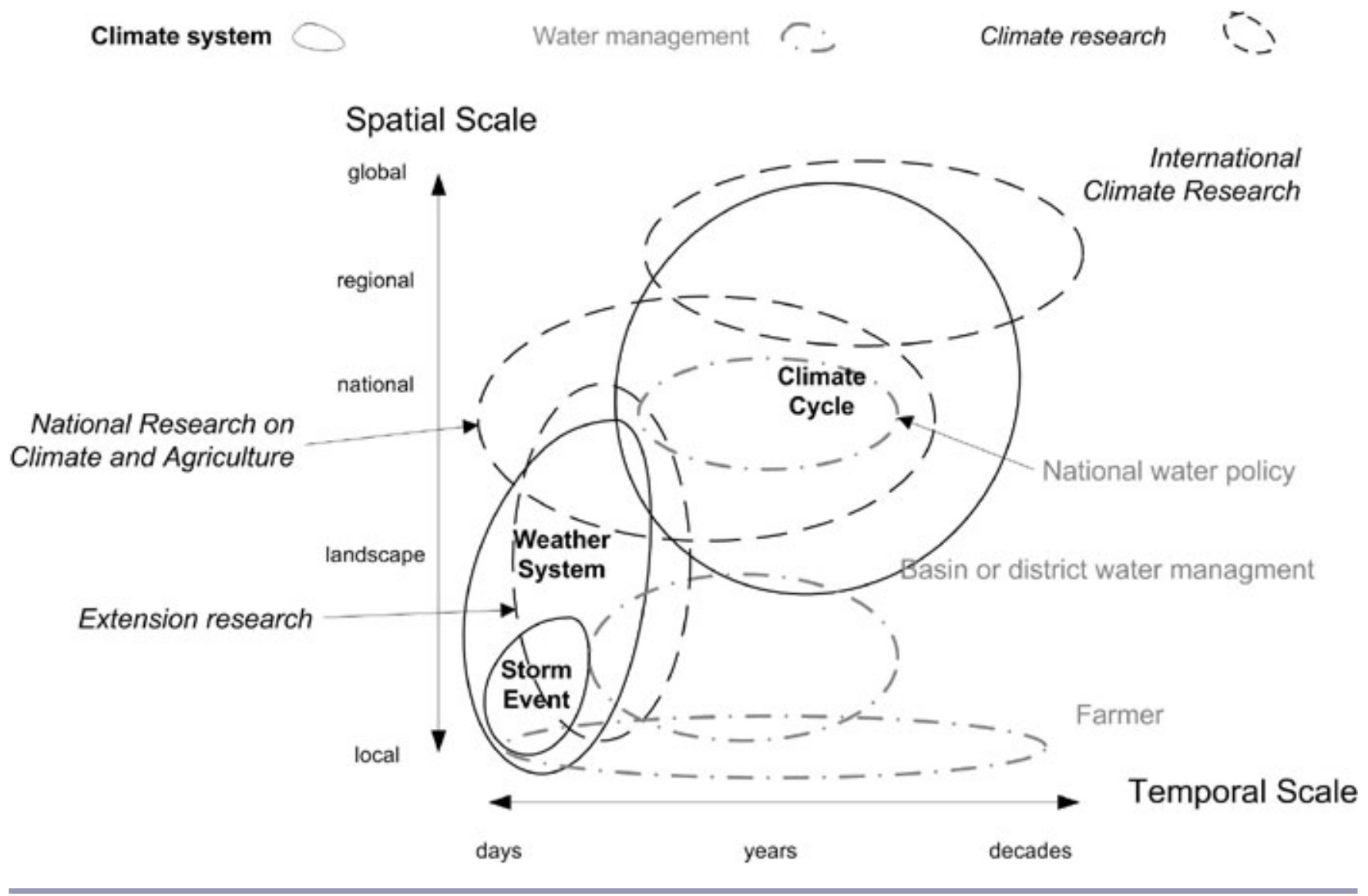

hunters engaged in the harvest of bowhead whales for subsistence purposes and the global regime for whales and whaling that has evolved under the terms of the 1946 International Convention on the Regulation of Whaling (Young 2006).

Institutional interplay in cross-scale and cross-level contexts can be highly asymmetric or relatively balanced. For example, when it comes to shaping formal laws and regulations on the use and allocation of water in the Mekong region, the central agencies of the state hold most of the power (Lebel et al. 2006). However, when it comes to the operational management of irrigation or flood protection, flexibility is included in the management system through "adjustments" made by communitybased institutions. Similar dynamics are evident in the interplay among government agencies, international organizations, and local communitybased resource users in the Caribbean (Adger et al. 2006). In Tobago, for example, the asymmetry in information between government agencies that control access to information on new legislation, zoning, and funding and local resource users is 
circumvented through newly developing international and regional networks of community-based organizations and advocacy groups. Hence, networks at different levels use a range of mechanisms to develop appropriate cross-level mechanisms of interplay.

\section{Co-management}

A wide range of studies has illuminated the advantages and challenges of co-management as a strategy to improve the understanding of complex multi-interest problems involving natural resources and the environment and their potential solutions in a multilevel world. The term co-management refers to a continuum of arrangements that rely on various degrees of power- and responsibility-sharing between governments and local communities. The evidence from an accumulation of empirical studies of co-management indicates two emerging conclusions.

First, many co-management cases are more complex than might be concluded from the common image of joint management as the sharing of power and responsibility between a unitary "state" and a homogenous "community." The state is rarely unitary, being an amalgamation of different branches, agencies, and political factions, and communities are a host of different interests, perspectives, and political actors (Carlsson and Berkes 2005). Second, successful co-management often arises from the adaptive, self-organizing processes of learning-by-doing rather than from an optimal power-sharing across levels (e.g., Singleton 1998, Berkes and Folke 2002, Folke et al. 2002). Olsson and his colleagues (2004) posit that several factors should be considered for co-management dynamics; these include building vision, leadership, and trust; enabling legislation to create political opportunities; monitoring the environment; combining different kinds of knowledge; and supporting collaborative learning.

Adger et al. (2006) show that the incentives for resource user groups to form alliances with other groups at the same level and to harness the knowledge of scientists and regulators at different levels through co-management often arise from a demand to redress historical patterns of power distribution. In the coastal communities examined, these cross-level interactions result in positive and progressive co-management arrangements. Linkages between organizations also develop across levels, in part because of self-interest. Berkes (2006) argues that co-management arrangements, as opposed to narrowly defined community-based management, may be essential for handling the cross-level dynamics of marine commons. In many cases, cross-level linkages develop to access information and provide benefit to linking agents through the use of this information (Lebel et al. 2006; P. Olsson, P., L. Schultz, C. Folke, and T. Hahn, unpublished manuscript). In terms of scientific knowledge in particular, access to externally validated information makes the information itself more trustworthy and the process of information gathering and analysis more legitimate. Access to credible science originating at different levels has been central to strategies of environmental advocacy groups as well as government agencies in a host of conflictual situations (Adger et al. 2006, Lebel et al. 2006).

\section{Boundary or bridging organizations}

Knowledge is often held, stored, and perceived differently at different levels, resulting from differences across levels about what is perceived as salient, credible, and legitimate knowledge, or what is perceived as the important scale or level of the problem, i.e., the plurality challenge. This scale challenge can be addressed by the management of boundary functions. Organizations that explicitly focus on this intermediary function are known as boundary organizations or bridging organizations (Guston 1999, 2001, Cash 2001, Folke et al. 2005; T. Hahn, P. Olsson, L. Schultz, and C. Folke, unpublished manuscript), because they play an intermediary role between different arenas, levels, or scales and facilitate the co-production of knowledge. An example in this issue is the Ecomuseum Kristianstads Vattenrike, which grew out of and continues to depend on issue networks to bring in and share information with stakeholders (see Olsson 2006). Whether formalized in organizations specifically designed to act as intermediaries or present in organizations with broader roles and responsibilities, several proposed institutional functions and characteristics seem to be important, including: (1) accountability to both sides of the boundary; (2) the use of "boundary objects" such as maps, reports, and forecasts that are co-produced by actors on different sides of a boundary; (3) participation across the boundary; (4) 
convening; (5) translation; (6) coordination and complementary expertise; and (7) mediation (Cash et al. 2003).

This can be illustrated in the case of aquifer depletion (Polsky and Cash 2005). A state-level water plan that might be salient to state actors who believe that water can best be allocated by aggregating it throughout the state might not be salient to local actors who feel that the plan not only fails to address local problems but in fact causes new ones. Regulations set by a state's department of water resources, although legitimate to state actors on the grounds that the state "owns" the water, would not be legitimate in the eyes of local landowners who feel that they should have some input into rules that affect their livelihoods. Assessment of the aquifer undertaken by a state's geological survey, although credible to state actors because of the quality of the personnel and the fact that the findings are peer reviewed, would not be credible in the eyes of local landowners who have a more in-depth understanding of local issues. In this particular example, boundary organizations have played critical roles in mediating the differences inherent in these conflicting perceptions and interests.

Leadership is often a key function of these boundary or bridging organizations. Olsson and his colleagues (P. Olsson, L. Schultz, C. Folke, and T. Hahn, unpublished manuscript) show how the staff of the Ecomuseum Kristianstads Vattenrike plays a key role as facilitators and coordinators in the adaptive co-management of the lower Helgea River catchment, Sweden. This process involves international associations; national, regional and local authorities; researchers; not-for-profit associations; and landowners. Leadership is important for developing and communicating a vision of ecosystem management for the area that can frame and give direction to the cross-scale or cross-level process. The current governance regime in Kristianstads Vattenrike is a highly flexible organizational solution that relies on cross-level interactions to help create integrated landscape solutions to problems that arise and match the scale of the problems. It is likely that, in this and many cases, without leadership that spans levels, the necessary social and institutional structures and processes to deal with cross-level dynamics will fail to emerge.

\section{CONCLUSION}

Our understanding of patterns of scale and crossscale dynamics in linked human-environment systems has advanced substantially in the past decade. There is now an impressive diversity of tools, approaches, and measures for studying scale and scale-related phenomena. The papers in this special issue illustrate that cross-scale and crosslevel interactions are pervasive, sometimes extremely important, and susceptible to identification and analysis. Against this progress, however, the papers in this special issue acknowledge that there is still relatively little understanding of the dominant mechanisms of cross-scale interaction, especially when analyses go beyond the more conventionally studied spatial, temporal, and jurisdictional scales.

From a management perspective, evidence is accumulating that supports the hypothesis that those systems that more consciously address scale issues and the dynamic linkages across levels are more successful at (1) assessing problems and (2) finding solutions that are more politically and ecologically sustainable. Whether the model is one of institutional interplay, co-management, boundary/ bridging organizations, or an integration of all three, a core proposition is that in a world increasingly recognized as being multilevel, solutions must be as well. The opposite poles of top-down approaches, which are too blunt and insensitive to local constaints and opportunities, and bottom-up approaches, which are too insensitive to the contribution of local actions to larger problems and the resulting potential for tragedies of the commons, are clearly inadequate in providing both socially robust information (Gibbons 1999) and viable management solutions. A middle path that addresses the complexities of multiple scales and multiple levels is much more difficult, but also what is required.

Responses to this article can be read online at: http://www.ecologyandsociety.org/voll1/iss2/art8/responses/

\section{Acknowledgments:}

This article is based on research supported in part by a grant from the U.S. National Oceanic and Atmospheric Administration's Climate Program Office (formerly the Office of Global Programs) 
through the Environment, Science and Development Program for the Knowledge Systems for Sustainable Development Project.

\section{LITERATURE CITED}

Adger, W. N., T. A. Benjaminsen, K. Brown, and H. Svarstad. 2001. Advancing a political ecology of global environmental discourses. Development and Change 32:681-715.

Adger, W. N., K. Brown, and E. Tompkins. 2005. The political economy of cross-scale networks in resource co-management. Ecology and Society 10 (2): 9. [online] URL: http://www.ecologyandsociety. org/vol10/iss2/art9.

Berkes, F. 2002. Cross-scale institutional linkages: perspectives from the bottom up. Pages 293-319 in E. Ostrom, T. Dietz, N. Dolšak, P. C. Stern, S. Stonich, and E. U. Weber, editors. The drama of the commons. National Academy Press, Washington, D.C., USA.

Berkes, F. 2006. From community-based resource management to complex systems: the scale issue and marine commons. Ecology and Society 11(1): 45. [online] URL: http://www.ecologyandsociety.org/ vol11/iss $1 / \operatorname{art} 45$.

Berkes, F., and C. Folke. 2002. Back to the future: ecosystems dynamics and local knowledge. Pages 121-146 in L. H. Gunderson, and C. S. Holling, editors. Panarchy: understanding transformations in human and natural systems. Island Press, Washington, D.C., USA.

Carlsson, L., and F. Berkes. 2005. Comanagement: concepts and methodological implications. Journal of Environmental Management 75:65-76.

Cash, D. W.2001. "In order to aid in diffusing useful and practical information": agricultural extension and boundary organizations. Science, Technology, and Human Values 26:431-453.

Cash, D. W., W. C. Clark, F. Alcock, N. M. Dickson, N. Eckley, D. Guston, J. Jäger, and R. Mitchell. 2003. Knowledge systems for sustainable development. Proceedings of the National Academy of Sciences of the United States of America 100:8086-8091.

Cash, D. W., and S. Moser. 2000. Linking global and local scales: designing dynamic assessment and management processes. Global Environmental Change 10:109-120.

Clark, W. C. 1987. Scale relationships in the interactions of climate, ecosystems, and societies. Pages 337-378 in K. C. Land and S. H. Schneider, editors. Forecasting in the social and natural sciences. Reidel, Dordrecht, The Netherlands.

Folke, C., S. Carpenter, T. Elmqvist, L. Gunderson, C. S. Holling, B. Walker, J. Bengtsson, F. Berkes, J. Colding, K. Danell, M. Falkenmark, L. Gordon, R. Kasperson, N. Kautsky, A. Kinzig, S. Levin, K.-G. Mäler, F. Moberg, L. Ohlsson, P. Olsson, E. Ostrom, W. Reid, J. Rockström, H. Savenije, and U. Svedin. 2002. Resilience and sustainable development: building adaptive capacity in a world of transformations. International Council for Science, Paris, France.

Folke, C., T. Hahn, P. Olsson, and J. Norberg. 2005. Adaptive governance of social-ecological systems. Annual Review of Environment and Resources 30:441-473.

Folke, C., L. Pritchard, F. Berkes, J. Colding, and U. Svedin. 1998. The problem of fit between ecosystems and institutions. International Human Dimensions Programme on Global Environmental Change, Bonn, Germany.

Gadgil, M., P. Olsson, F. Berkes, and C. Folke. 2003. Exploring the role of local ecological knowledge for ecosystem management: three case studies. Pages 189-209 in F. Berkes, J. Colding, and C. Folke, editors. Navigating social-ecological systems: building resilience for complexity and change. Cambridge University Press, Cambridge, UK.

Gibbons, M. 1999. Science's new social contract with society. Nature $\mathbf{4 0 2}$ (Supplement):C81-C84.

Gibson, C., E. Ostrom, and T.-K. Ahn. 1997. Scaling issues in the social sciences: a report for the International Human Dimensions Programme on Global Environmental Change. International Human Dimensions Programme on Global 
Environmental Change, Bonn, Germany.

Gibson, C., E. Ostrom, and T.-K. Ahn. 2000. The concept of scale and the human dimensions of global change: a survey. Ecological Economics 32:217-239.

Goldman, M., editor. 1998. Privatizing nature: political struggles for the global commons. Rutgers University Press, New Brunswick, New Jersey, USA.

Gunderson, L. H., and C. S. Holling, editors. 2002. Panarchy: understanding transformations in human and natural systems. Island Press, Washington, D.C., USA.

Guston, D. H. 1999. Stabilizing the boundary between politics and science: the role of the Office of Technology Transfer as a boundary organization. Social Studies of Science 29:87-112.

Guston, D. H. 2001. Boundary organizations in environmental policy and science: an introduction. Science, Technology, and Human Values 26:399-408.

Holling, C. S. 1986. The resilience of terrestrial ecosystems: local surprise and global change. Pages 292-316 in W. C. Clark and R. E. Munn, editors. Sustainable development of the biosphere. International Institute for Applied Systems Analysis, Cambridge, UK.

Holling, C. S. 1995. Sustainability: the cross-scale dimension. Pages 65-75 in M. Munasinghe and W. Shearer, editors. Defining and measuring sustainability: the biogeophysical foundations. United Nations University/World Bank, Washington, D.C., USA.

Kates, R. W., William C. Clark, Robert Corell, J. Michael Hall, Carlo C. Jaeger, Ian Lowe, James J. McCarthy, Hans Joachim Schellnhuber, Bert Bolin, Nancy M. Dickson, Sylvie Faucheux, Gilberto C. Gallopin, Arnulf Gruebler, Brian Huntley, Jill Jäger, Narpat S. Jodha, Roger E. Kasperson, Akin Mabogunje, Pamela Matson, Harold Mooney, Berrien Moore III, Timothy O'Riordan, and Uno Svedin. 2001. Sustainability science. Science 292:641-642.

Lansing, S. 1991. Priests and programmers: technologies of power in the engineered landscape of Bali. Princeton University Press, Princeton, New Jersey, USA.
Lebel, L., P. Garden, and M. Imamura. 2005. The politics of scale, position and place in the management of water resources in the Mekong region. Ecology and Society 10(2): 18. [online] URL: http://www.ecologyandsociety.org/vol10/iss2/ art18.

Meadowcroft, J. 2002. Politics and scale: some implications for environmental governance. Landscape and Urban Planning 61:169-179.

Millennium Ecosystem Assessment. 2005. Ecosystems and human well-being: synthesis. Island Press, Washington, D.C., USA.

Olsson, P., C. Folke and F. Berkes. 2004. Adaptive co-management for building resilience in socialecological systems. Environmental Management 34:75-90.

Ostrom, E., J. Burger, C. B. Field, R. B. Norgaard, and D. Policansky. 1999. Revisiting the commons: local lessons, global challenges. Science 284:278-282.

Ostrom, E., T. Dietz, N. Dolsak, P. C. Stern, S. Stonich, and E. U. Weber, editors. 2002. The drama of the commons. National Academy Press, Washington, D.C., USA.

Pastor-Satorras, R., and A. Vespignani. 2001. Epidemic spreading in scale-free networks. Physical Review Letters 86:3200-3203.

Polsky, C., and D. W. Cash. 2005. Drought, climate change, and vulnerability: the role of science and technology in a multi-scale, multi-stressor world. Pages 215-245 in D. Wilhite, editor. Drought and water crises: science, technology, and management issues. Marcel Dekker, New York, New York, USA.

Scott, J. C. 1998. Seeing like a state: how certain schemes to improve the human condition have failed. Yale University Press, New Haven, Connecticut, USA.

Singleton, S. 1998. Constructing cooperation: the evolution of institutions of co-management. University of Michigan Press, Ann Arbor, Michigan, USA.

Star, S. L., and J. R. Griesemer. 1989. Institutional ecology, 'translations' and boundary objects: 
amateurs and professionals in Berkeley's Museum of Vertebrate Zoology, 1907-39. Social Studies of Science 19:387-420.

Wilbanks, T. J., and R. W. Kates. 1999. Global change in local places: how scale matters. Climatic Change 43:601-628.

Young, O. 2006. Vertical interplay among scaledependent resource regimes. Ecology and Society 11(1): 27. [online] URL: http://www.ecologyandso ciety.org/vol11/iss1/art27.

Young, O. R. 2003. The institutional dimensions of environmental change: fit, interplay, and scale. MIT Press, Cambridge, Massachusetts, USA. 